Design Studies (Volume 66, Jan 2020)

Luke Caspar Pearson

\title{
A Machine for Playing In: Exploring the videogame as a medium for architectural design.
}

\begin{abstract}
This paper aims to investigate what is unique about videogame spaces and their construction, and how they might be utilised by architects. This design-led study establishes videogames as an architectural medium through practice-based research projects, examining game worlds as architectural spaces by developing design methods to analyze their environments. It then discusses developing games as architectural representations combining virtual space with computational rules. The paper's final study suggests how game structures might be applied in design approaches for ostensibly real sites. Through four case study projects, I outline a new form of architectural design practice operating between physical and virtual, reflecting the cultural influence of game worlds and exploring videogame environments as new ways to 'realise' architecture.
\end{abstract}

\section{Key Words}

Architectural design; case studies; conceptual design; design methods; videogame design.

\section{Paper}

Many videogames released today are highly spatial and architectural in their settings. Players can travel the world, or other worlds, obtaining improbable abilities and shaping the environment around their actions. Although games are typically marketed as entertainment, this inherent spatiality suggests they could be adopted as a media for designing architecture. For that to happen, we must understand game worlds from the position of architectural design methods, uncovering their potential through design research as opposed to predominantly textual analysis. This approach has been one that I have adopted in my own research and by examining game spaces through tools and methods common to architecture I can reveal the nature of their spatiality in a different manner to research performed by games 
studies or media studies theorists. This in turn leads me to generate new hybridised forms of architectural design that incorporate methods from game development, resulting in work that I frame as architectural yet is designed to be realised through, or realised in, virtual game spaces.

Game spaces offer new possibilities for architects to represent and realise projects as virtual worlds structured by computation. Game engine software is becoming increasingly democratized and the two main platforms, Unity and Unreal are both ostensibly available for free. In many ways it has never been easier for an architect with an interest in the field of games to incorporate the design of virtual worlds into their practice. However, such an endeavour will invariably require a new form of design vocabulary that operates between architecture and games, reflecting both the similarities and the divergences in how they treat space.

Over the past twenty years, there has been considerable scholarly literature about videogames, with a smaller subsection of this devoted specifically to the construction of virtual worlds. Some of the most important work examining the relationship between these worlds and architectural theory comes from Steffen Walz (2007 \& 2010) and Michael Nitsche (2009). However, these engagements leave open the question of how this directly affects architectural design practice. This question is more pressing given that this research is now around a decade old, in which time cultural influence of videogames has grown exponentially alongside the proliferation of free, professional-grade game design tools.

There are already significant examples of the lines between virtual game spaces and physical architecture being blurred. In 2016 American game developers Niantic released Pokémon GO, an augmented reality smartphone videogame based on the franchise created in the mid-1990s by Satoshi Tajiri. Pokémon GO blended the real world with the logics of a highly successful game series. It was significant for architecture because videogame values started to become attached to real, physical locations. This happened because Pokémon GO's game world is derived from digital maps of the physical world which are experienced at one-to-one by the player [Fig.01]. 


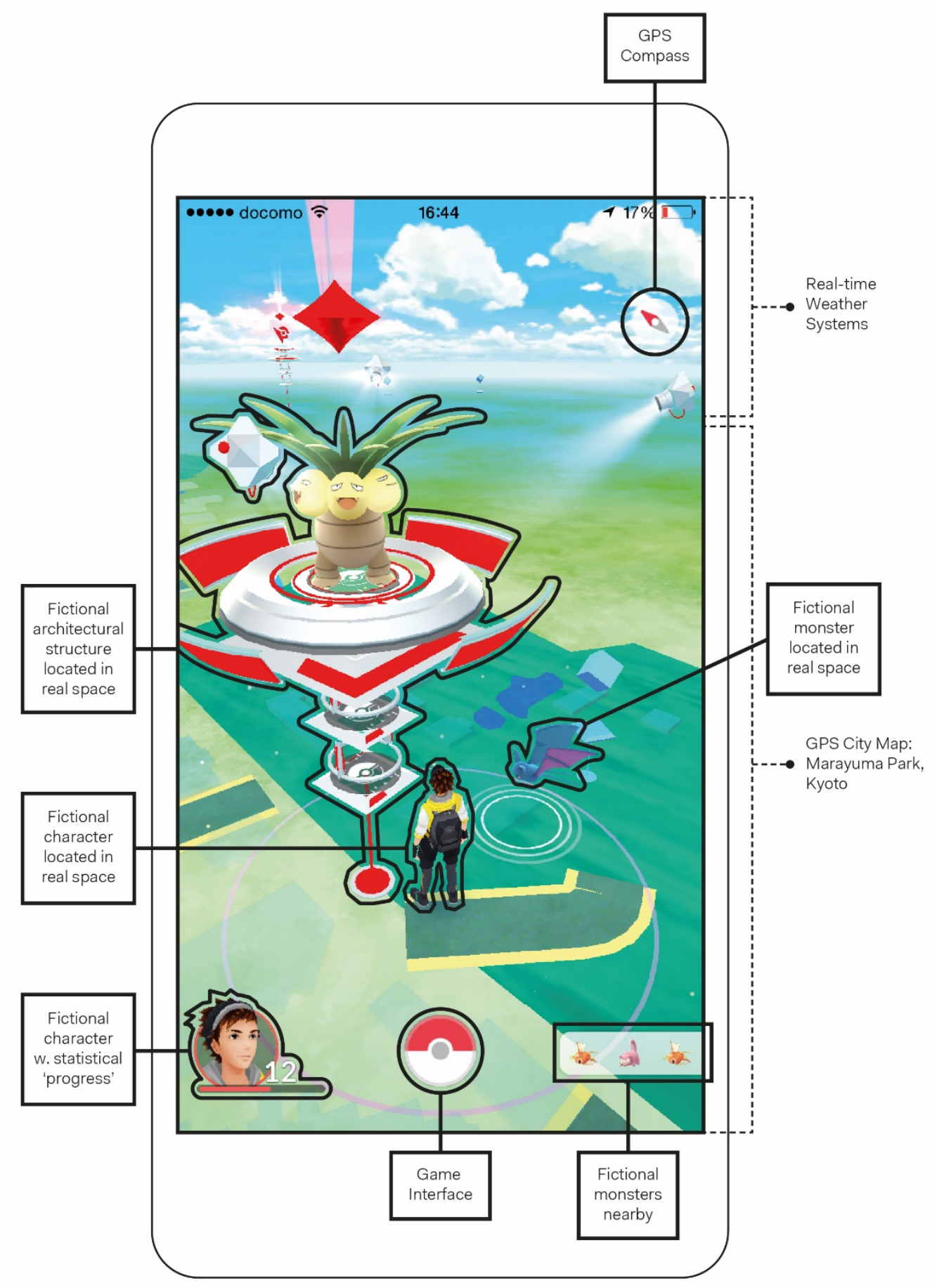

In the game, players chase strange creatures through a GPS mediated version of their surroundings. Local landmarks from bars to graffiti to university faculties are 
demarcated as PokéStops-nodes within the game where the player can pick up bonus items to aid in their quest. This combination of geolocation and augmented reality was not new to games, but Pokémon GO quickly became a social phenomenon. Larger discussions followed the release of the game, concerning the legal and social ramifications of imposing fictional values, derived from real data, back onto the city. Affluent urban areas tended to have higher monster density than poorer neighbourhoods and private property lines were violated by Pokémon hunters (Manaugh, 2016). While Pokémon GO aptly demonstrates that the distinction between 'real' and virtual spaces is disappearing, studies such as Jones' reinforce that 'virtual environments are [...] just as valid phenomenal conceptions as their physical counterparts' (2013: p 1).

As such, this study explores the impact of games on architectural design by placing games into context as architectural representations. I use design projects to examine their environmental composition, while simultaneously using theory to assess their place in the cultural landscape of architecture. I follow this by discussing how the structure and aesthetics of game spaces might be incorporated into design approaches that blur boundaries between spatial practice in the virtual and physical.

\section{Architecture of the 'Half-Real'}

In the case of Pokémon GO, the physical city is intrinsic because the game overlays a fiction onto reality at a 1:1 scale. But this alignment is a tacit structure of all videogame worlds. The Danish videogame theorist Jesper Juul (2005: Loc 41) describes game worlds as 'half-real'. Juul argues there is an interplay between fictional settings, the game environment, and real rules-the systems by which we succeed or fail in the game. A rule could be as simple as jumping a gap in Mario (1985-2019) or a complex ecology of material relations as in Minecraft (2009). Both of those games have a notional fiction which justifies the player's presence and actions in the world. This relationship ties games into what we can call 'speculative' design, which in architecture has produced fictional projects that explore the rules of reality. Examples of this range from Piranesi's quasi-fictional mappings of Rome in the $18^{\text {th }}$ century, Archigram's fantastical techno-cities of the 1960s to Bjarke Ingels' contemporary discussion of 'worldcraft' (2015). 
In their theorisation of the half-real world, Juul and other games studies theorists provide structural definitions of games that I use to build my own framework for analysing the videogame in relation to architecture and architectural theory. I integrate these readings of games with my architectural design techniques to establish new methods for comparing the structure of game worlds to other forms of architectural representation. Understanding this structure is important because wherever we look in games, we tend to find architecture. Pokémon GO treats the real city as a tabula rasa populated by game iconography. Minecraft (2009) has been utilised by organisations such as the RIBA and UN Habitat as an educational tool and its emphasis on first-person building recalls pre-Renaissance construction where the architect would direct matters onsite. Much has also been written about the SimCity (1989-2014) series, and Cities: Skylines (2015) as city-builder games, although neither of these games offer the player much opportunity to design individual buildings, instead mainly focussing on zoning (Lobo, 2008: p 208).

The depiction of architectural space has been fundamental to the conception and development of games as a medium, from the days of pixelated pseudo-3D worlds through to the near-photorealism of today. $Q^{*}$ bert (1982), Age of Empires (1997) and Shadowrun Returns (2013), amongst hundreds of others, use isometric viewpoints. Nintendo designer Shigeru Miyamoto's original designs for Super Mario Bros. (1985) that defined a genre of 2D platformers were cross-sectional drawings constructed on graph paper. Nowadays games not only depict space but leverage it as a game mechanic in unique ways. The Nintendo series Splatoon (2015-2017) involves players wielding paint guns to mark territory across levels using ink, with the winners being the team that has colonised the most space. Even 2018's hit game, Fortnite (2017), which is a 'last player standing' shooter game involves the player battling opponents while recycling building materials from the environment into components to rapidly fabricate structures in the landscape. While lacking the social programme, these mechanisms echo both mass-produced and self-built architecture systems, from Kisho Kurokawa's Nagakin Capsule Tower to Elemental's Quintana Roo.

Strikingly, the architectural morphology of these game worlds is entirely linked to the systems of the games they underpin, 'in which players engage in an artificial conflict, defined by rules, which results in a quantifiable outcome' (Salen and Zimmerman, 2003: p 80). In Shadowrun Returns, isometric space is divided into squared units, 
with each character able to move a specific distance in a 'turn'. What is, on the surface, a near-future cyberpunk world of slick corporate facilities and sewers, is revealed as a pure organisational grid. Rather than Le Corbusier's Modulor or other anthropometric systems for designing buildings, this grid is tied not to proportion but to actions that are given a numerical value. Its architectural design not only represents built structures but also foregrounds what Juul calls 'immaterial support, namely the upholding of the rules, the determination of what moves and actions are permissible and what they will lead to' Juul (2005: Loc 526). The player's actions within space are regulated by these rules and success typically requires embracing the 'aesthetics of repetition' (Grodal, 2003: p 148) that games offer. Architecture in games performs a dual function of providing a contextual background but also as Coyne argues, ensuring that 'whatever the goals or quests of the game, these work to enable us to keep on repeating' (2004: p 203).

Videogame worlds are therefore layered conditions, where representations of space exist alongside rules for their interaction (Nitsche, 2009). What my design research approach adds to this dialogue is to subject game spaces to the kind of visual and spatial architectural analysis that the predominantly textual readings of game studies research do not. Where Nitsche outlines the coded layer of game space that sits 'below' the represented world on screen, my method is to visually and spatially reveal how these codes shape the world. The development of my own hybridised design practice between architecture and games gives me a clearer understanding of how these formal properties come about. An architect might not know that a game world's visual form (its 'mesh renderers') can be very different to its implied physical extents (its 'colliders') but a game designer would.

Adopting an architectural design approach is important because game designers regularly use real-world locations as the inspiration for virtual worlds, such as Assassin's Creed Unity's (2014) realistic recreation of the Notre-Dame. Yet the virtual cathedral still possesses many new details peculiar to its game function including ledges to hang from and pathways to tiptoe across. Theorists such as Espen Aarseth have framed games as 'allegories of space' that 'rely on their deviation from reality in order to make the illusion playable' (2000: p 169). To see the allegory as a way of structuring space in games foregrounds the referential, emphasising Craig Owens' argument that 'the allegorist does not invent images but 
confiscates them' (1980: p 69). In short, objects and spaces in games are never what they seem even when there is ostensibly a clear story or spatial setting on the surface. This means that even some of the most straightforward means of analysing and quantifying their architecture - exploring, recording, drawing and mapping game worlds using design techniques - allow me to reveal these deviations from reality and understand them as a series of transformations that architecture must undergo to be effective as part of a game environment.

My research uses multiple methods and entry points - from critical drawing to data mining - to unpeel these layers and subject videogame space to architectural analysis. I see this as a productive act, the aim of which is not simply to produce a set of information about existing game worlds. Instead I outline their morphology to propose new forms of architectural language and approaches for designing between the virtual and physical, reflecting how game spaces now have cultural influence as places in their own right. If game worlds seem to 'require exaggerated form, colour and spectacle' (Coyne, 2003: p 207) then I am attempting to quantify those exaggerations and apply them back into a design practice working between architecture and games.

In this context I will now discuss four different design projects that have emerged from my research, moving from two projects that peel apart game space to scrutinise it, into the design of an architectural game and finally applying these principles into an experimental urban scheme.

\section{Using the 'distancing' effect of drawing to unravel virtual game environments.}

For me to understand how game environments operate, I need to play them, to 'complete the circuitry' (Stewart, 2016). A game world cannot truly exist without its player, but developers often go to great pains to cultivate a proper, cinematic experience within these settings. To judge their operational structure, we can disrupt them by playing against the system. I do this through 'cheat codes' that allow my player's avatar to break their encoded bonds and explore the spaces that lie beyond. Cheats are a long-held facet of game design and culture, and the code I use in this research—entitled 'noclip'-is ubiquitous across many game titles, first appearing in the seminal 1993 first person shooter (FPS) game Doom. 
'Clipping' is the act of stopping a game avatar's movement through an artificially imposed boundary (Carmack, 2012). Given that virtual materials have no inherent 'physical' form, the game engine must be told which objects are solid. Solidity and visibility can be mutually exclusive in game worlds. For Duncan Jones, solidity and gravity are used 'to provide a phenomenon; something we can interact with to provide us with a conception of reality' (2013: p 18). Noclip is a cheat which suspends the player's ability to hit objects. This creates new and unexpected phenomena, introducing new conceptions into the game world. Primarily, cheat codes allow me to access and reveal all the constructional habits and tricks that distinguish level design from architectural design and vice-versa. American media theorist Daniel Reynolds defines such cheat commands as 'virtual world naturalism,' arguing they allow wandering exploration as 'a form of counterplay that remakes a game, in a more free-form, exploratory way, out of its own raw materials' (2010). I see my own practice in similar terms, using the raw material of game worlds as the basis for producing architectural spaces through drawing.

I have used the noclip cheat code to explore several games all built on Valve Corporation's Source Engine including the seminal Half-Life 2 (2004). I take in-game screenshots as architectural photographs, exploring levels in a 'ghostly' fashion that produces glitches. I then classify my screenshots in relation to repeated types of spatial phenomena that I have observed and so establish typologies of behaviour. From this, I produce hand-drawn, inked architectural drawings that transfer and formalise these properties into an alternative media. Each drawing is an archetype of a certain architectural phenomenon the cheat code enables.

My practice reveals that spatial continuity in a played experience of a first-person game is often facilitated by fragmentary compositional arrangements of game objects in the environment. My screenshots use the standard first-person camera, emphasising the compositional interplay between 3D geometry and 2D graphics within the game world rather than analysing the game's raw graphic files or code. The point of this is to emphasise how contingent game spaces are on both the rules which constrain the player and the limitations on how they can be viewed. One simple code fundamentally changes what the camera is allowed to see, revealing the game world as a field of discrete elements rather than a contiguous topology. 
I use my screenshots to understand repeated behaviours caused by the cheat code, from which I create architectural drawings of the spatial types I have observed. By providing a degree of separation from the source material, I believe this act of drawing can be considered a method for translating game spaces into understanding as architectural spaces themselves, framing them in a new light. In this regard I see the drawing as Robin Evans' 'intervening medium' (1997: p 156) where 'the subject matter [...] will exist after the drawing, not before it' (1997: p 165). For Evans, the space appears after the drawing and similarly my drawings are interventions to remove the game environments from the sphere of games and frame them as architecture. Yet the glitches I find and frame through drawing only exist because of the way the game space is constructed to impart meaning upon the player. Such phenomena would not be present in a 3D model of a building construction.

Although all screenshots are taken from the standard first-person perspective, my drawings diverge into isometric, elevation and perspective allowing me to distance myself from what a player sees. My ability to use architectural representation as a tool to interrogate game spaces aligns with American games theorist John Sharp's readings of similar virtual art practices as 'a space for exposing the questioning the peculiar trajectory of 3D videogames toward even greater verisimilitude' (2015: $p$ 48). My work can be compared to that of artists such as Harun Farocki (Parallel I-IV, 2012-2014), and JODI (Max Payne CHEATS ONLY, 2006), who have made several video-based projects exploring the artificiality of game worlds, although they have not been interrogated in an architectural design-based context. By moving into handmade architectural drawings, I can obtain further productive degrees of separation. Shorn of 'realistic' textures, and turned into lines, my process generates architectural studies of the behind-the-scenes compositions that create a sense of place for the game player.

My drawings represent what media theorists Bolter and Grusin call 'remediations' (2001) of videogame space, the refashioning of an interactive, digital media into the physical artefact of the paper based architectural representation. I believe this process can be compared to Villem Flusser's notion of the 'black box' as the invisible workings of the camera-machine (2006: p 26). In a game played as intended, there is a relationship between input and output that becomes evident to the player, such as axial movements using the keyboard and camera controls using the mouse. But 
when I use cheat codes to play in a transgressive fashion, the camera itself also becomes a participant in creating strange phenomena, caused precisely by the compositional techniques the game designers have used. Breaking the game can reveal more of its essential workings.

Amongst all the phenomena I have observed and recorded, several techniques appear regularly and can thus be seen as intrinsic parts of game space architecture. I will now discuss some notable examples that have repeatedly emerged.

\subsection{Skybox}

A 'skybox' is notionally a box that encapsulates a game level, using a 'cube mapped' texture to produce a seamless sky across the game world. This allows designers to suggest expansive spaces in the background of a scene without modelling large amounts of backdrop geometry and helps the game become less memory intensive. In Half-Life 2, the architecture of the game's setting, City 17, is built around a giant structure called The Citadel. The Citadel generates a form of architectural procession, a building constantly looming in the background of levels as the final destination point of a circuitous journey taken by the player. In this context the game world could be seen as similar to Picturesque architecture that 'attends to the direction of movement and sight like the gardener whose rule is to never let the foot travel the path of the eye' (Macarthur, 2007: $p$ 157). Here The Citadel functions as 'a destination [...] revealed but its access must be discovered' (Macarthur, 2007: p 157).

To maintain this consistent visual presence, the game designers employ certain spatial techniques that are revealed through my counterplay. Although the player ultimately enters The Citadel in the game's linear story, in earlier stages the structure is created partly as navigable geometric space and part mapped skybox images [Fig.02]. 


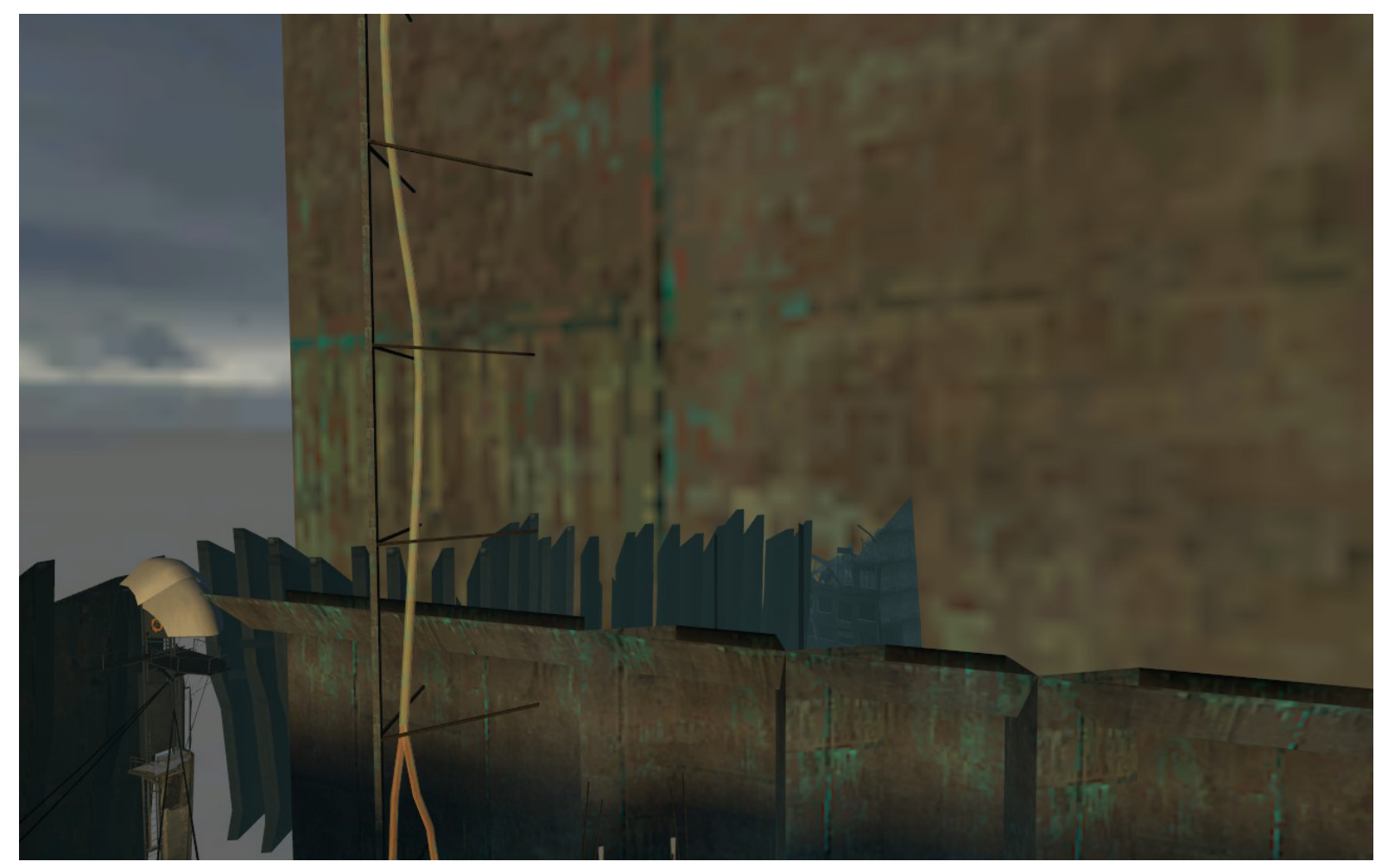

The skybox works like a dynamic movie matte painting, splicing two and threedimensional depictions together and allowing the large and complex structure to be visually ever-present and yet computationally efficient. This approach recalls Andrea Pozzo's designs at the church of Sant'Ignazio in Rome, where a fake dome painted onto the ceiling is revealed at a certain viewing point, blending into the geometry of the building itself.

By examining the specific points at which this connection takes place, I can subvert the designed route through the world that places The Citadel as the focus. Here the result of my drawing method is to show that the process of generating a grand procession across discrete levels relies on such schisms - discontinuous 3D models that meet projected images to help imply continuous environments. The consistent linework of my drawing reinforces that this fragmentation operates as one unified system to generate game space. [Fig.03] 


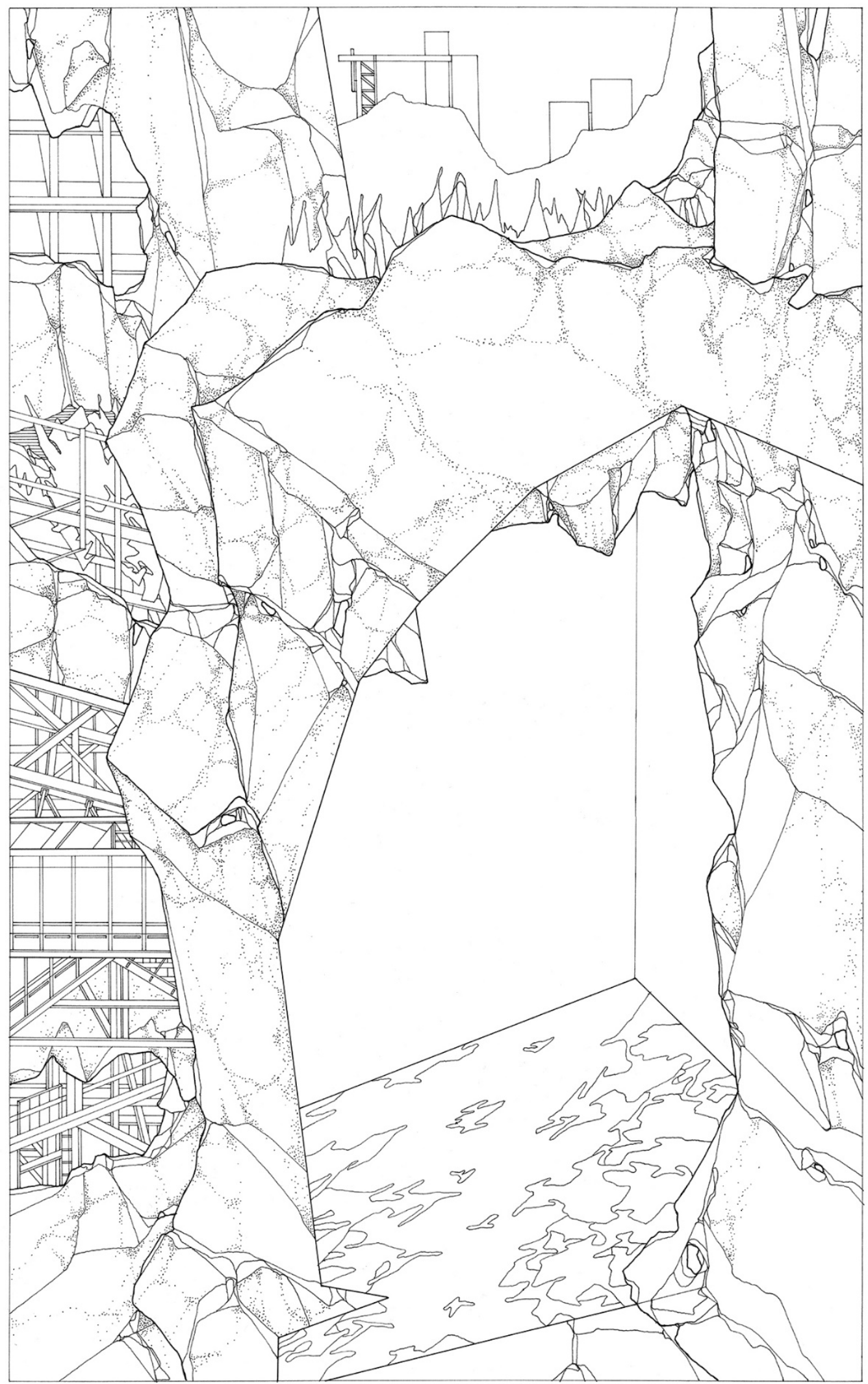




\subsection{Hall of Mirrors}

One of the most visually evocative phenomena I regularly observed is a well-known effect colloquially called 'hall of mirrors.' This is visual stretching and repetition of the virtual camera's view arising from a confusion about what it should be rendering.

Being able to ghost through walls using cheat codes means I can subvert their function in the game as visual (not structural) enclosures. As Robert Venturi remarked, 'since the inside is different from the outside, the wall—the point of change-becomes an architectural event' (1977: p 86). Unlike his conception of the wall as a zone, in a game world the wall has no thickness meaning I can sit directly between interior and exterior. At this point the virtual camera becomes confused as to what it should be rendering: space strobes, stretches and reflects, requiring multiple screenshots to capture.

This creates a progressive typological distortion of the camera's view frame by frame. My drawing reflects the fact that such internal envelopes often exist due to the amount of work required to render complex and layered scenes in real time. This is why so many games still take place in narrow corridors. In response, my drawing reflects the progressive distortions caused by wandering outside the envelope as errors combine frame-by-frame. To draw in this way uncovers the fact that these visual phenomena are produced by the irrepressible, consecutive rendering of frames of the virtual camera which has been removed from its normative path. [Fig.04] 


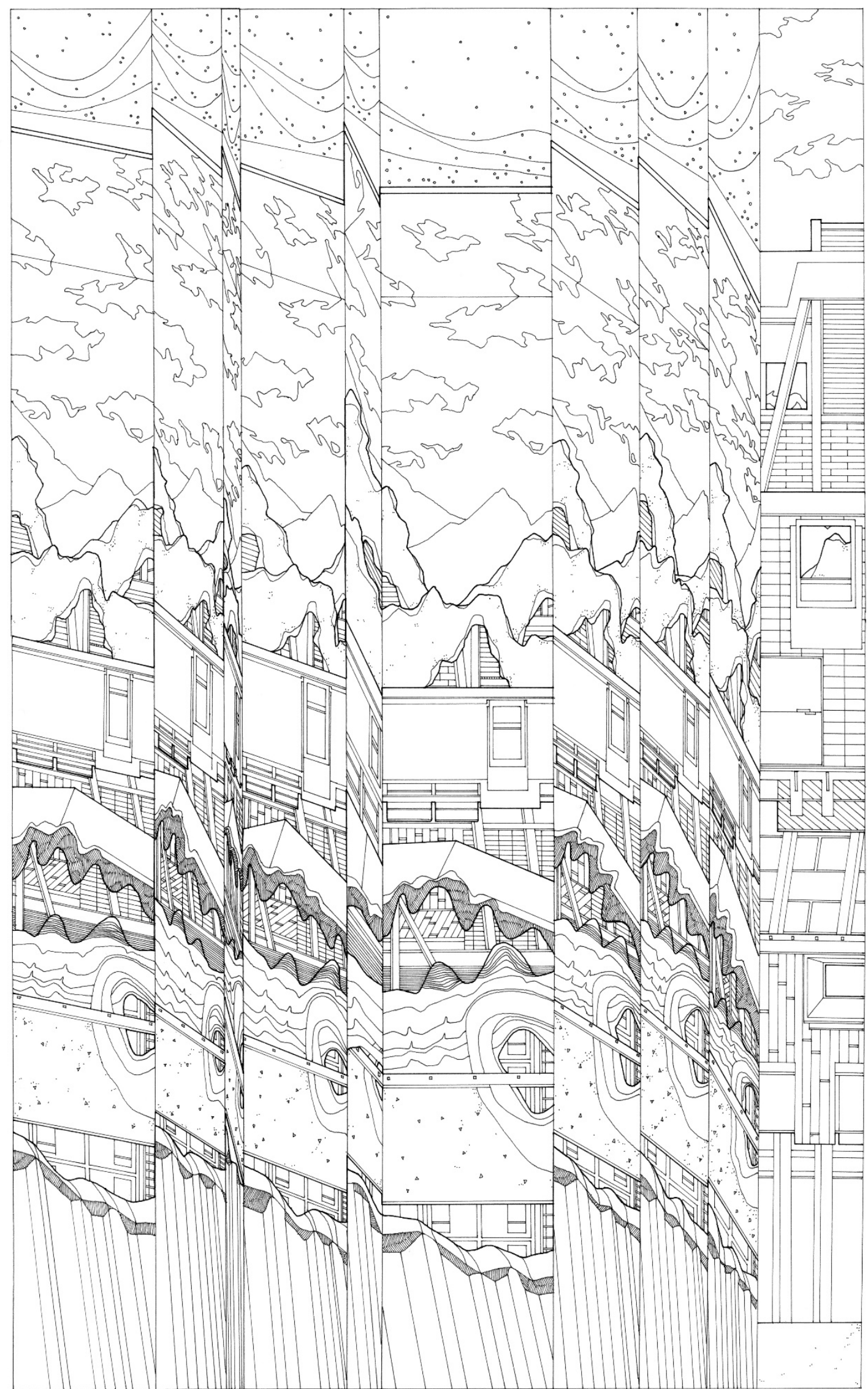




\subsection{Dissolving Space}

As I move my avatar to the edge of the game space, moving far beyond the compositional confines of the game level, I also face deviations in the behaviour of virtual lighting systems and fog-as if the camera is trapped between two different aperture settings. The camera attempts to render a scene from much farther than anticipated, and the view becomes increasingly overexposed. In a typical experience of a Source Engine game, 'bloom' lights create naturalistic looking scenes and fog is used to hide objects far from the camera (for computational efficiency) in a convincing manner.

Yet once away from the intended path, my avatar's camera becomes unable to discern the constructed scene and the environment breaks down into pure illuminated brilliance. Space dissolves in front of the camera and I transcribe it into patches of emptiness within the drawing, bounded by lines. We can argue that on Flusser's 'significant surface' of the computer screen both the solid and the void are as spatial as one another, (2006: p 8) in the end, they are all pixels. My line drawing is an alternative, but similar, way to equalise different forms of spatial information, and make invisible borders visible. [Fig.05] 


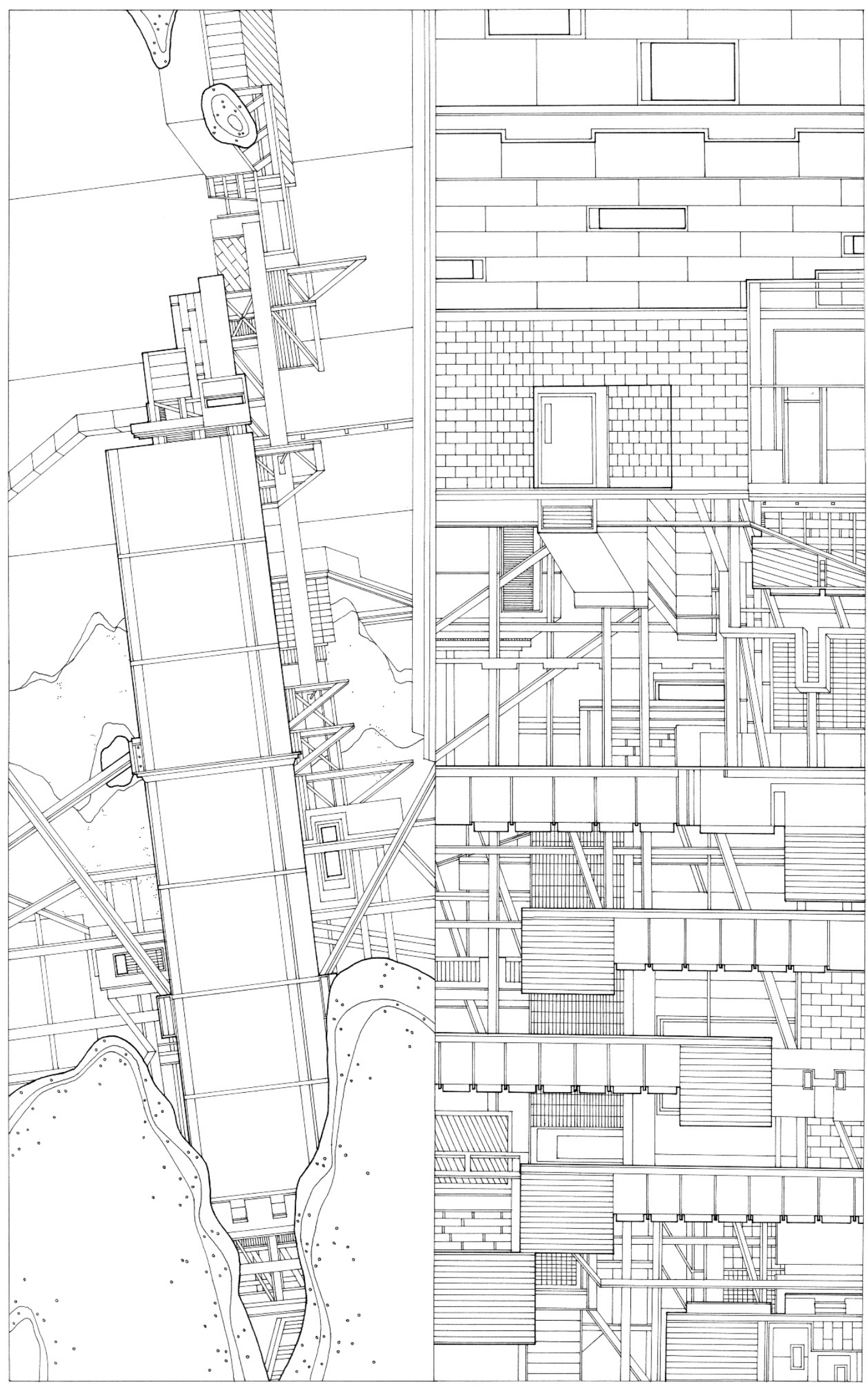




\subsection{Unravelling the game world}

Further drawings examined a multitude of other architectural conditions that emerge within disrupted game worlds. Underwater Distortions details how water is portrayed merely by surfaces with a material attached, replicating ripples through random 'noise' algorithms. The player is never usually invited to swim to the edge of a body of water, because noclip reveals only a finite geometrical enclosure. By entering objects only designed to be seen as external props, or moving out towards clouds and rain showers I can see more of how these total virtual environments are actually composed of many individual fragments. In Background Towers and Superscaled Apartments, positioning my avatar towards the hinterland of an urban scene traps the camera between the skybox and physical geometry, where modelled residential towers meet those mapped onto a flat surface. Here the generic 'Eastern European' housing blocks of City 17 become grossly overscaled, blurred and distorted.

Read together, these drawings constitute the Noclip World, a taxonomy of virtual architecture derived from the rupture of the carefully cultivated videogame world [Fig.06]. 

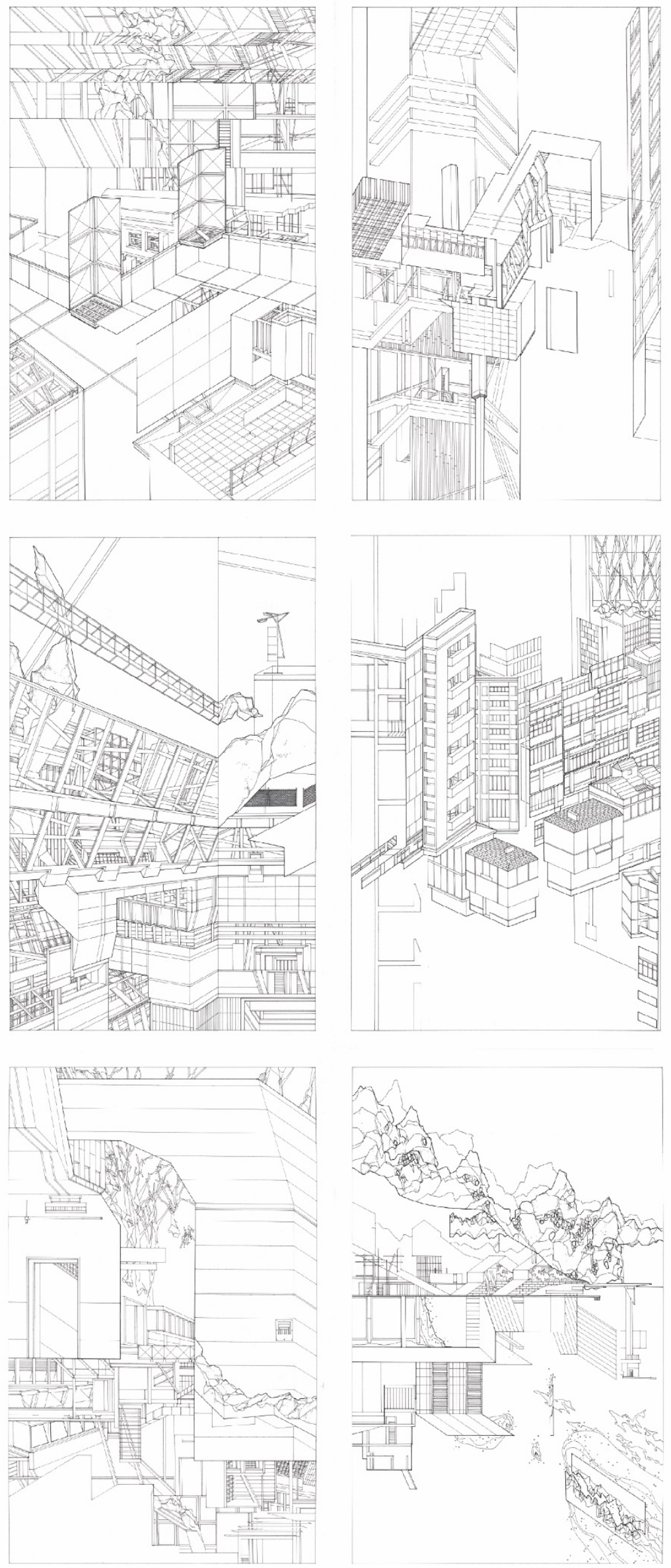
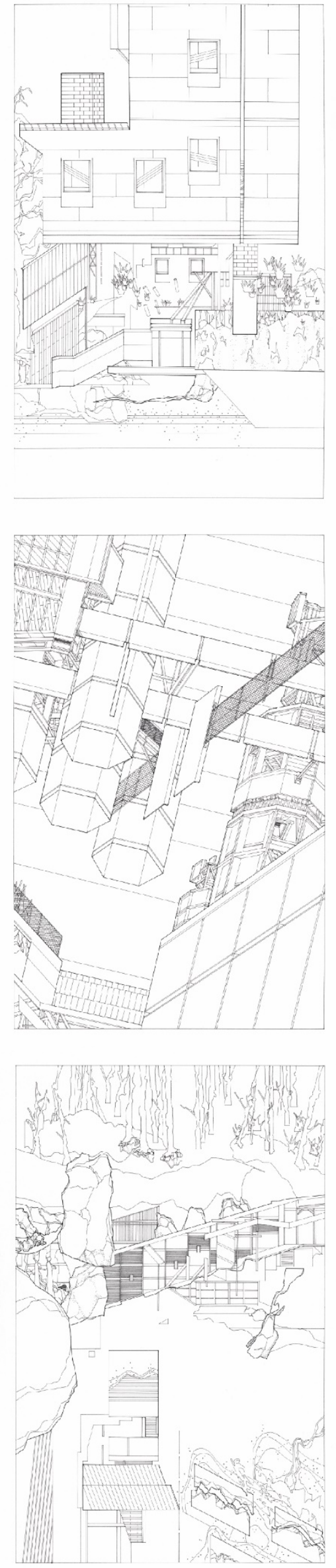
My research provides an alternative reading of videogame space, away from the drive for realism and seamless narrative. Drawing becomes the tool to expose

glitches in virtual videogame environments and reveal the contingency that underpins even the most realistic digital depictions of space. When we play a firstperson game, we are typically the most powerful inhabitant of the world and the game space reflects that as worlds that begin and end around the player. Here, architecture, weather, sun light, visual perception and physics are all designed around the player's view. By moving away from that viewpoint and interrogating these spaces through other media, I establish that their fragmentary construction is their defining characteristic. The morphology of game environments is the creation of continuous architecture through discontinuous elements.

\section{Learning from Los Santos}

As Juul argues, there are both material and immaterial structures to games. Much of the time, the material world represented in a game might offer a different message to the immaterial structure of its rules. To understand this most clearly, it is helpful to examine a game that directly recreates a real place, allowing comparisons to be made. Learning from Los Santos is a project I produced as a series of studies exploring Grand Theft Auto V (2013), a game which offers a very realistic looking depiction of Los Angeles as the backdrop for all number of criminal transgressions focussed around driving. The huge range of vehicles open to the player in Los Santos - the game's deviant Los Angeles-has the effect of instigating a landscape of pure movement. What my design research intends to uncover, is how the 'immaterial structure' of the game world makes arguments beyond the visually enticing depiction of LA. The title of this research is inspired by Venturi, Scott Brown and Izenour's seminal study into the symbolic workings of Las Vegas, and I see my own work as reemphasising their approach of 'form analysis as design research' to understand the 'method not content' (1973: p 6) of Vegas' architecture. As they argue, Las Vegas played with the iconography and symbolism of history, twisting it into new forms towards capturing public desires, and I read Los Santos in a similar way through its deviation from reality (Aarseth, 2000: $p$ 169) and how this regulates its architecture. 
While we use analog sticks on the gamepad to control the player and the car, one simple button press allows the player to quickly change and steal vehicles.

Condensing the stealing of a car into one depression of a button trivialises it as an action. Rather than sticking to the domain of our own personal car, nearly every car is available to us. The car becomes everything and nothing. Or rather nothing as a singular vehicle but, I would argue, everything as the ethic of a city designed around total mobility. As one plays GTA $V$ its mechanics emphasise it as a city of movement. There may be a visual similarity to LA's freeways and boulevards, but such journeys are rarely as liberating in reality. Los Santos is not geographically accurate to LA but driving through something that looks similar-under the auspice of mechanics that turn it into a total zone of movement-is intoxicating. All this works towards the notion that we are in some form of ur-LA, where beyond the verisimilitude of the game's visual presentation of a city, it speaks to us more through mechanics that emphasise mobility. In this respect, we could argue for Los Santos as a reemphasis of Reyner Banham's famous proclamation that 'Los Angeles is the language of movement. Mobility outweighs monumentality there to a unique degree' (2009: p 5). In this context, I establish a reciprocity with historical figures who first brought LA to light as a subject of serious architectural inquiry. Yet as my design research reveals, Los Santos' version of mobility is more intensely structured than either one's real experience of LA or Banham's reading of it.

One way I have examined this has been to map and compare the systems of Los Santos to that of Los Angeles proper, to analyse the ways in which it compresses and distorts space around the player as an architectural structure that emphasises mobility [Fig.07]. 


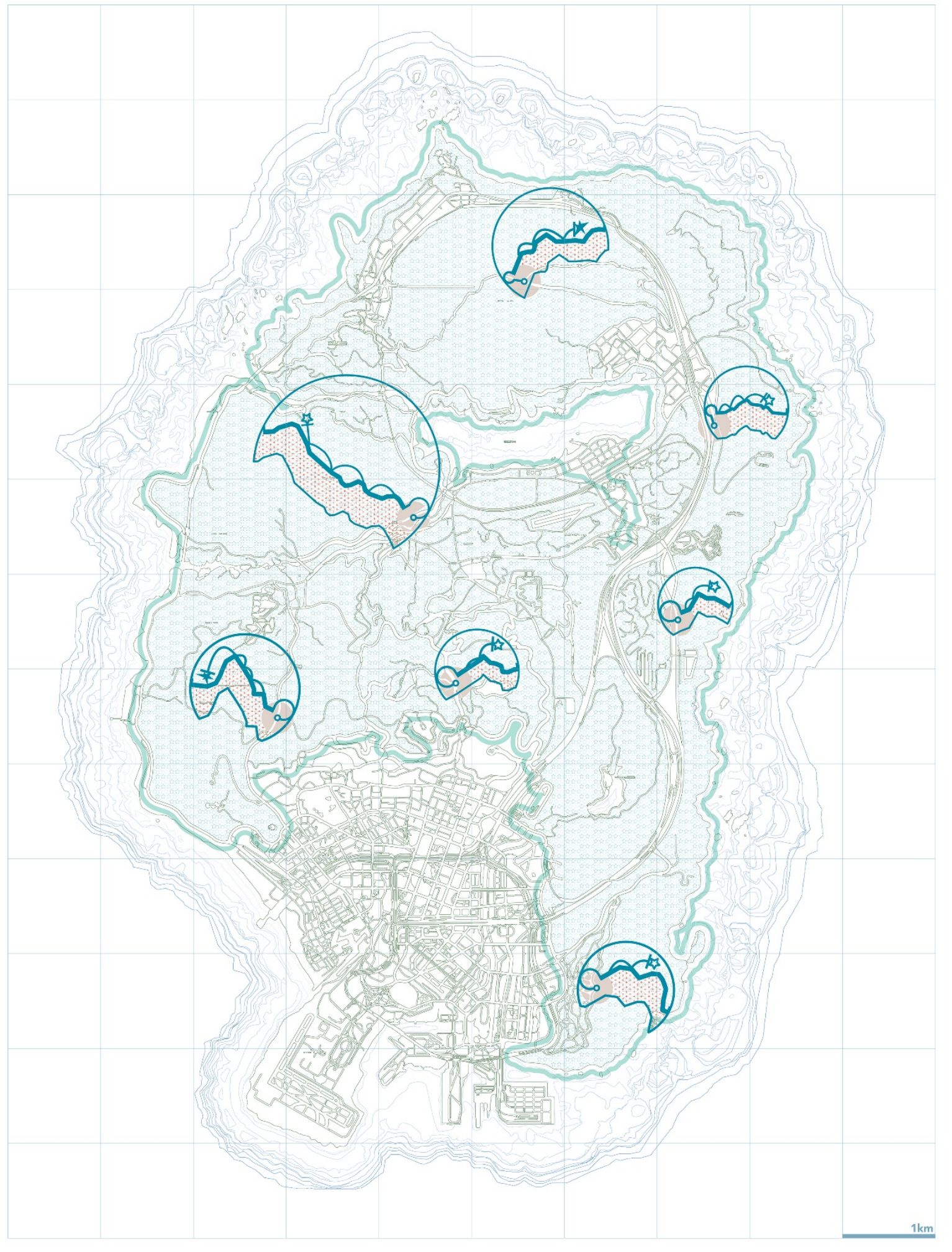

To demonstrate how small Los Santos is by comparison, I overlaid two digital facsimiles of LA together-Google Earth's rendition of the city, drawn from laser and satellite surveys and Los Angeles as reinterpreted in Rockstar's hand-crafted world. Using an ultra-high-resolution map of Los Santos produced by the GTA V 
community, I was able to impose the extents of the virtual city onto Google's accurately scaled satellite maps of Los Angeles [Fig.08].

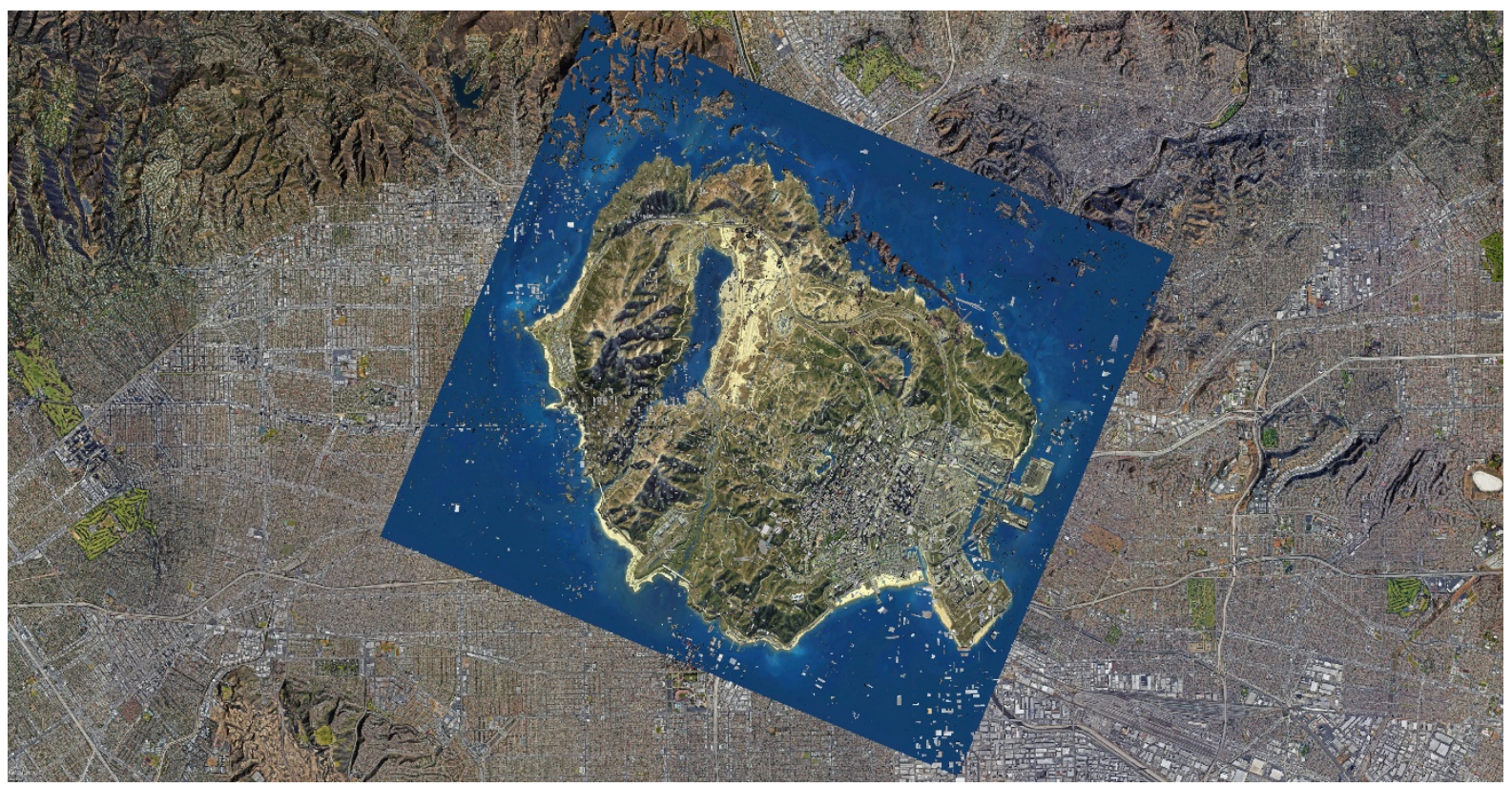

Viewed from an orbital scale, the difference in size is marked. This imposition was centred around City Hall, showing how the outer fringes of LA's sprawl have been particularly compressed.

What this reveals is that as game academics lan Bogost and Daniel Klainbaum point out, GTA games tend to work with 'an emphasis on how cities are perceived rather than on their objective realities' to produce 'equivalent, yet abstract representations of key Los Angeles spaces' (2006: Loc 3130-3210). Los Santos has never matched the true form of the original city, instead emphasising its atmosphere through a compressed and twisted cityscape with key buildings as markers. This in turn reinforces a state of perpetual movement, where journeys that may take hours in reality are experienced in minutes if not seconds without feeling unduly accelerated.

Playing the game as architectural 'fieldwork' allows me to develop other design methods which draw out the complexities of the systems that run beneath the surface of the game. I use several tools to delve into the files that make up the game, finding filenames and references to buildings within Los Angeles (such as The Standard Hotel on Sunset Boulevard) despite the game using fictional names for every area within the game. This allows me to compare the real-life source material used by the developers to their recreation of the city. I also again use screenshot 
photography, also contextualising the work in relation to the history of artists who have recorded Los Angeles. By generating a series of Ed Ruscha-style 'small' books comprised of screenshots using his 'deadpan' style, I compare Los Santos' morphology to that of LA, finding that the biggest ruptures occur through the smallest tweaks-a lone supercar impossibly high up a hill betraying cartoon physics, or gas stations permeating a world without fuel. I also produced a recreation of Banham's 1972 documentary Reyner Banham Loves Los Angeles using in-game characters, visiting many of the same real-life locations as Banham. I seek to more properly articulate the deviations of a virtual LA by using multiple analytical methods that were directly applied to the real city in the past. This allows me to 'draw out' the ways in which Los Santos is distorted from reality, however gross or subtle, and establish a set of information about this morphology, held together as one research project. While there are many issues to be raised with the content and morals of the GTA series, examining their relationship to reality offers me clues as to how I might incorporate them into my own design practice. The power of an immaterial structure, and by extension the videogame itself, is in establishing rules that impart a certain set of values upon the player within a virtual space. As a form of architectural representation, game spaces work by not only portraying virtual worlds (as a render or video might) but by allowing navigating and interaction with that world under a set of rules. While Los Santos is designed as part of a piece of entertainment, its methods and how it speaks about reality present powerful tools for designers to reflect on the world and unpeel its systems. [Fig.09] 


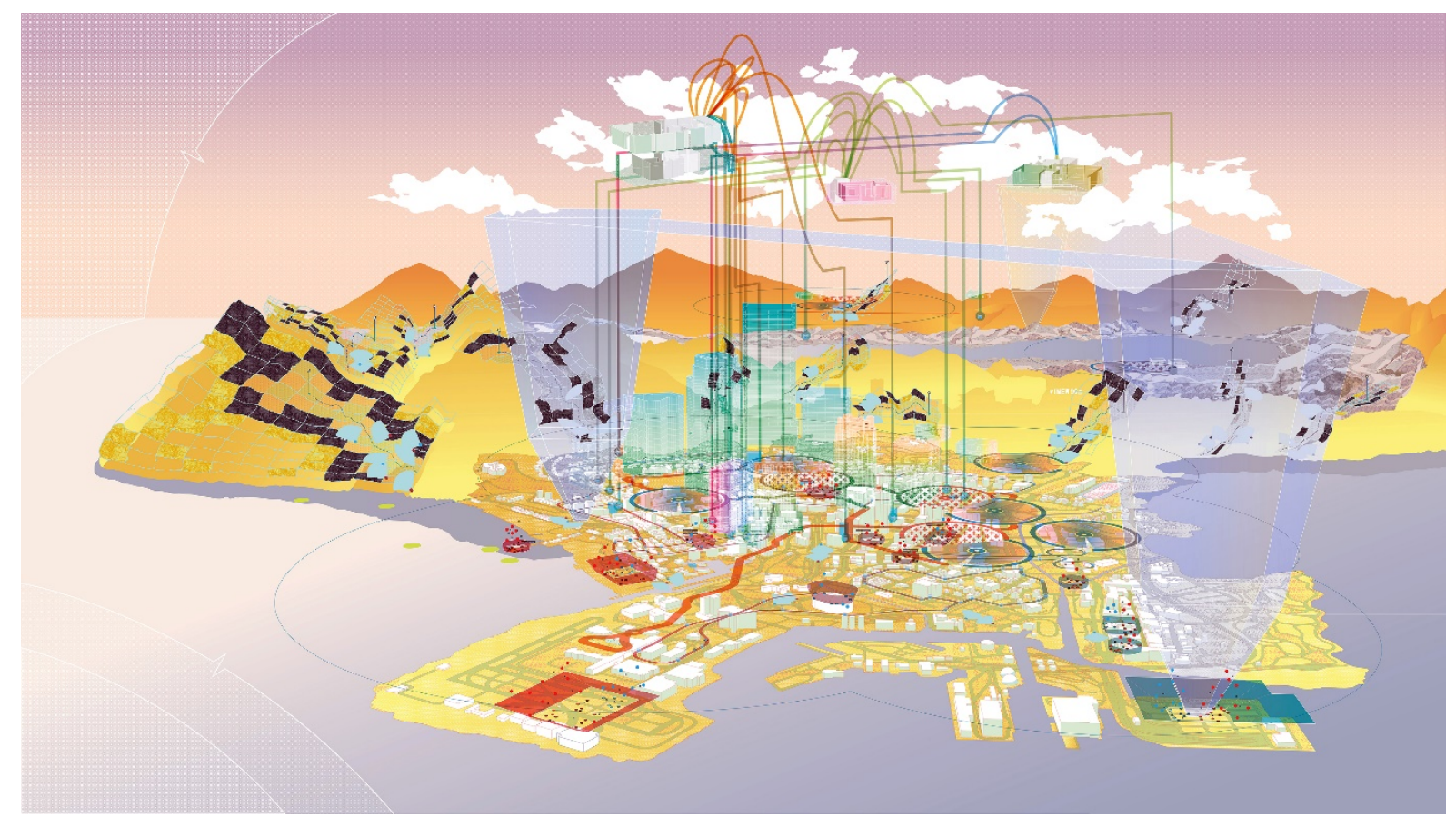

Following what I have learned from Los Santos, my work has developed into the design and production of games themselves, to explore their potential as a new medium of architectural representation.

\section{London Developers Toolkit}

At this point I would like to discuss directly using games as a form of architectural representation. The London Developers Toolkit is a game I have developed as a response to various articles in the press and public movements in reaction to London's changing skyline. In the game the player is responsible for building and then advertising a high-rise luxury development. The game has the loose appearance of a 'city-builder' such as SimCity but actually focuses on the production of advertising images for a residential building. The tower is generated randomly after the player undertakes a small series of tasks, which in turn brings those tasks and the design of images into focus. [Fig.10] 


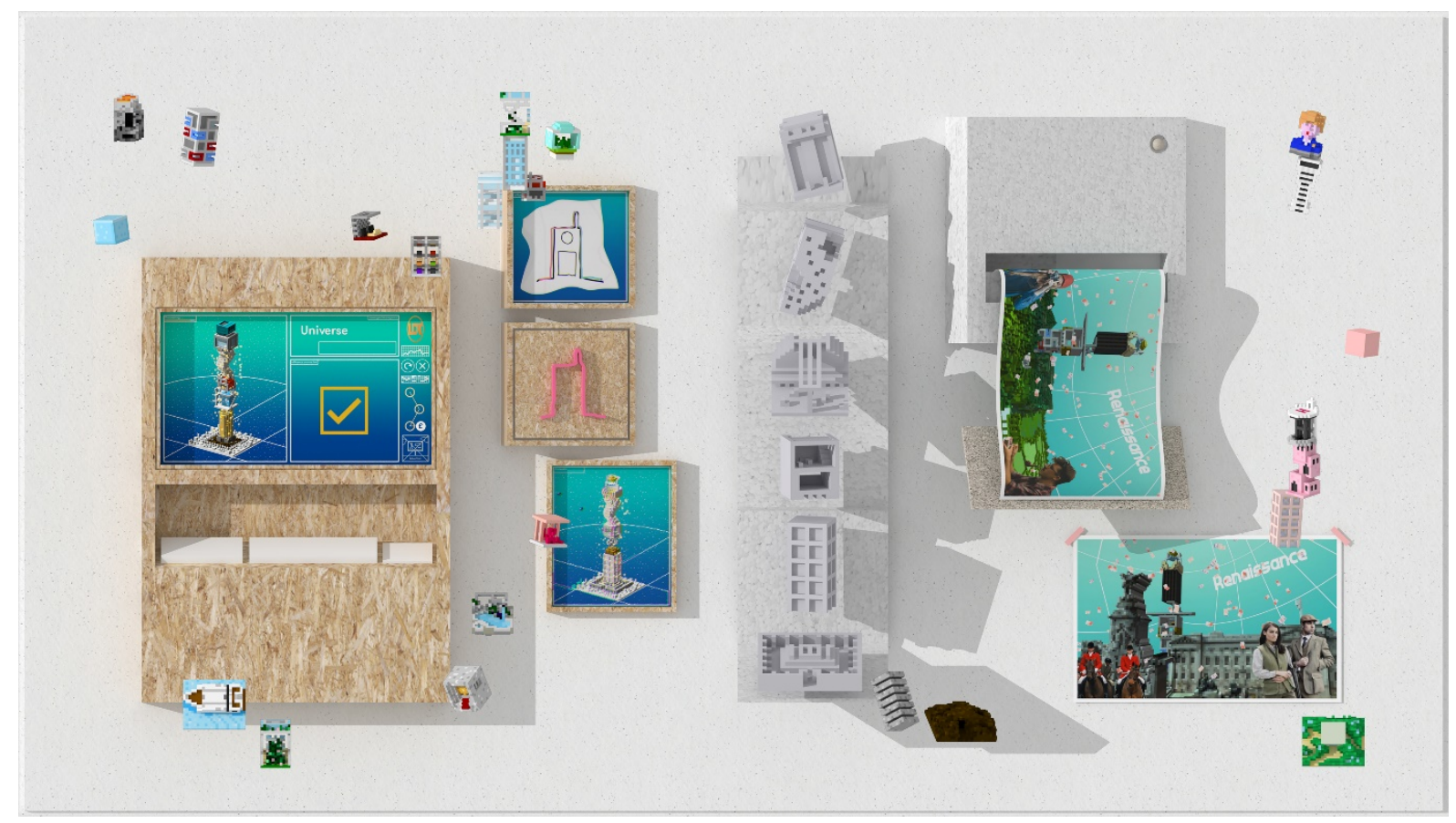

In its limited interaction and focus on process the game might be seen as a digital extension of Habraken and Gross' concept design games used to 'study design actions by producing an environment that is manipulable and well bounded' (1988: p 151).

Other games tackle similar urban issues, like Nova Alea (2016) which is a gamebased polemic on the property market. Described as 'an abstract game on the forces that shape our cities' (2017) it is the work of Italian game designer Paolo Pedercini, who is one of the leading creators of political and satirical videogames. Using a simple interaction of clicks to buy and sell buildings that grow until the 'bubble bursts', the game makes its message by focussing on one concept to 'extract an aspect from reality and enlarge it' (Habraken and Gross, 1988: $p$ 152). While my game also retains a similar focus, The London Developers Toolkit speaks more specifically about the architectural imagery that accompanies flows of capital in the city. My game instead interrogates the visualisations and renders that package and sell the desire for new developments and the lifestyles this implies. Such images are both designed architectural drawings (in the modern sense) and advertisements. The game establishes an immaterial structure that is limited but precise in what it asks of the player, who is notionally operating as an architect for a pair of property developers. They undertake three steps before a 'poor Photoshop' programme is 
made accessible and the player can design their own advertising images for their tower.

Visually, the game is predominantly constructed using a 'Minecraft-style' voxel modelling programme. I use this as it gives each element within the game the same blocky and abstracted style. Some elements are drawn from media reports, and analysis of real building programmes while others are fictional. Using voxel models allows me to equalise all these elements, making them cartoonish, even cute. This cuteness has agency however, and I use it to challenge 'the habitual by toying with it from a position of playful vulnerability' and 'lightheartedly probe[s] the established ways in which we invoke power' (May, 2019: p 47). The colourful and blocky visuals are designed to invite the player to become comfortable with scenarios that are drawn from real, pressing concerns.

\subsection{The napkin sketch}

The first stage of the game the player must complete is to adequately reproduce a 'napkin sketch'. This action is taken from the cliché of the master architect dispensing their visions on bits of tissue to a starstruck client. To replicate this act within the game, I use a gesture recognition interface so that the player directly draws into the virtual environment. Although gestural interfaces are now very common, tying this to the act of drawing opens a link to age-old mechanisms of architectural reproduction and pedagogy: tracing.

To build up a set of recognisable gestures I train my system through inputs. My napkin sketches were first produced as 'actual' sketches using a tablet before being hand-transcribed into the system. Each sketch is of a caricature drawn from buildings we have seen erected in London. By tracing each sketch at least 10 times into the system, I built up an average gesture path that corresponded to each drawing. The closer the player gets to this path, the higher they rate. As the player receives a random sketch to trace, the system analyses what they draw and awards a score. Anything within $90 \%$ accuracy is deemed 'inspirational' enough to proceed to the next level. Fail and the player must start the process again. All the possible sketches are held in a database that the code checks against as the player attempts to produce the correct gesture [Fig.11]. 


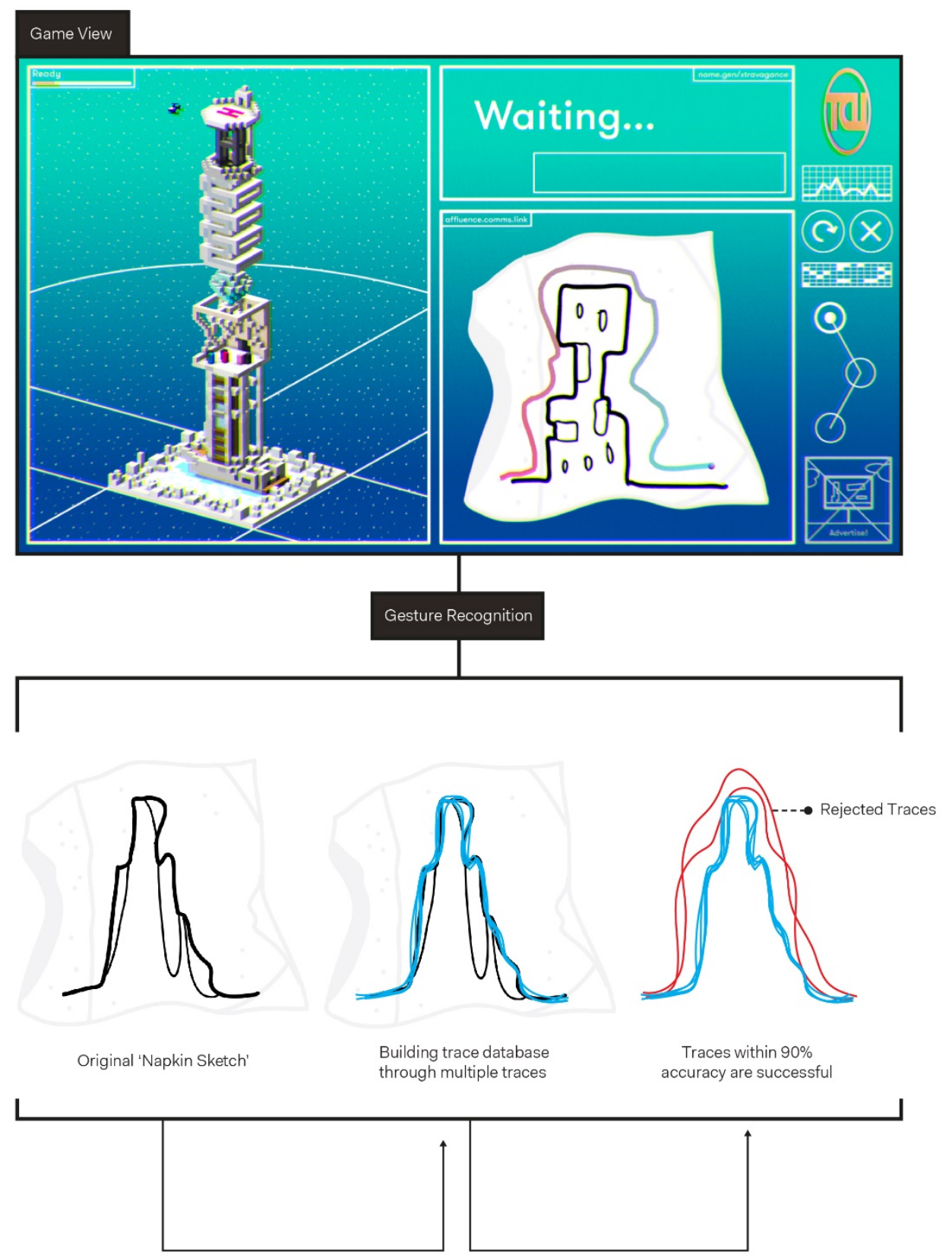

This interface emphasises tracing as a repeated act through repetitive game interfaces. It is not a tool for design, but one to articulate design process. A game is highly suitable for exploring this as, Coyne argues, 'design is already imbued with the repetitive impetus, through historical reference, copying, mimicry, and the 
workings of the play of meaning, right through to the labour of drawing and drafting.' (2003: p 203). While we must perform an action of dexterity, we are essentially tasked with tracing another drawing and achieving an acceptable likeness to it. While the sketch and the trace are both forms of drawing, they are divergent ones.

To return to Robin Evans, this act of tracing reinforces his contention that 'drawing is, from the beginning, a divided activity, resolvable into a prior act of thought and a consequent manual undertaking' (1997: p 164). In my tracing interface I imply that the prior act of thought was performed by someone else, leaving only the manual undertaking to be performed by the player. This tracing must accord to certain standards of accuracy, as defined by the game. This is a comment on 'iconic' architecture and the connection to capital that folds such buildings into a style that Charles Jencks has termed 'Generic Individualism' (2016) where wanting to stand out is a standardised position.

Following this, the player is asked to define a series of parameters the building should have and carefully balance this number so as not to make the building either too expensive to build, or too lacking in facilities to attract the proper clientele. They then need to identify and remember which boroughs of London have agreed to allow the construction of such a tower. These interfaces are derived from 'rhythm games' and 'brain training' applications respectively, that are more about remembering information and making the right action at a specific time, rather than actually designing the building. Following this process, a new layer of creativity opens up for the player, and they can produce their own 'glossy renderings' like those seen across the hoardings of London.

At this point the player can set the font and colour of text (the tower's name is randomly generated) and set different variables to create a finalised image. Various contextual scenes from London are provided, as well as human figures representing the aspirational clientele of the development. Players can set the weather conditions through changing the 'skybox' (as explained in the Noclip World section of this paper), and they can apply various image effects which are animated in real time. I allow players to create screenshots and combine this with an overlaid graphic that turns the camera view into a cut out and keep drawing. Although the initial stages of the game are not a design tool, this creative mode turns the game into a basic form 
of 'cultural software': the software which Lev Manovich describes as being used to generate culture (2013) — by giving the player means to create their own architectural imagery [Fig.12].

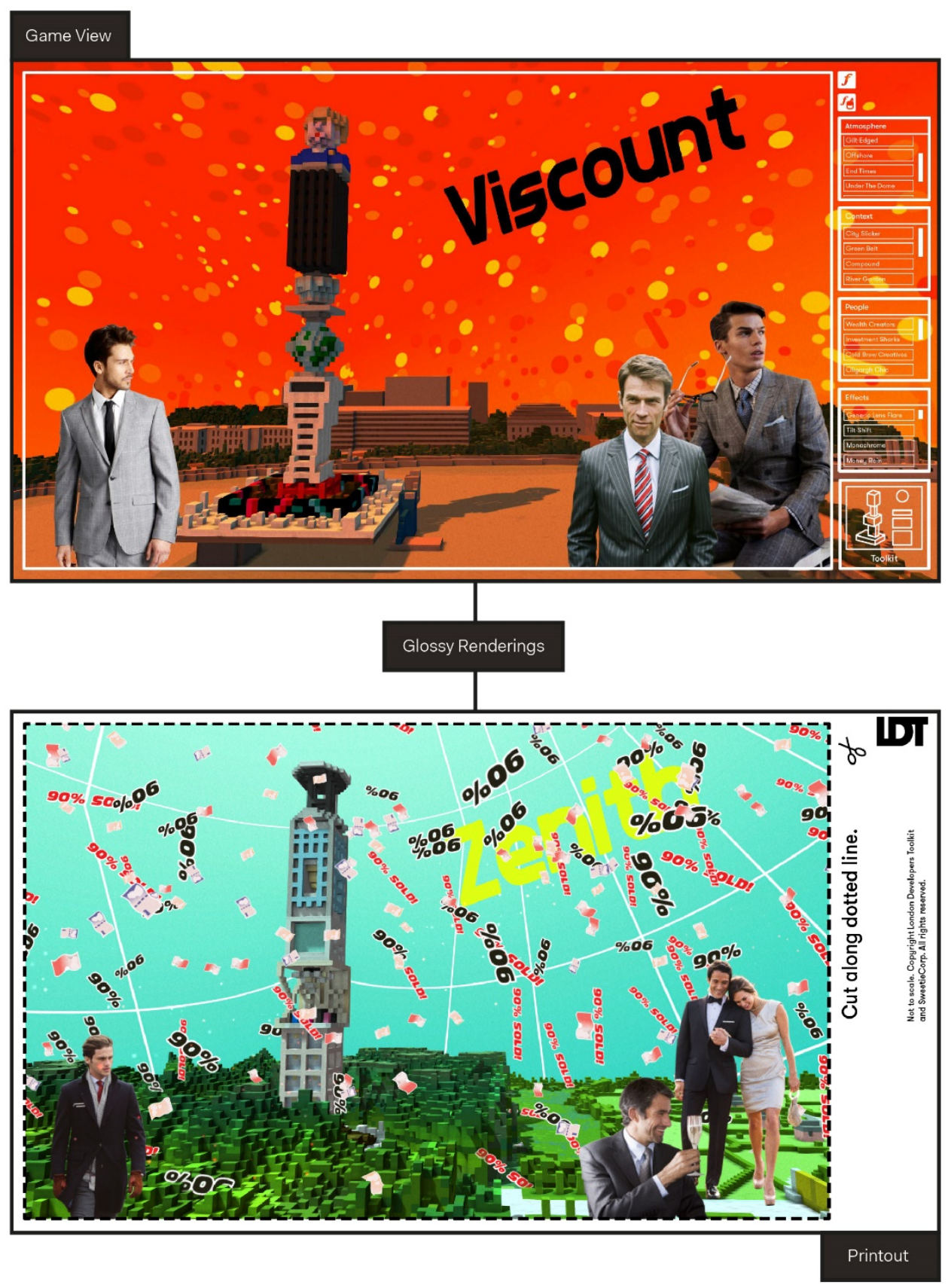


The player's agency is mainly limited to the drawing - the production of renderings. The game explores the relationship between architecture and the tools by which its images are designed, 'tools for changing and assembling form' (Radford, 2000: $p$ 381). Conventional city builder games purport to offer unlimited potential, but then hamstring the player with issues such as (low, American-level) taxation that are only uncovered by playing them (Williams, 2015). By comparison The London Developers Toolkit is a satirical game that seeks to unpeel the regime of images that help drive the property market today.

Although this is a game about architecture, it also demonstrates how the layers of a game space may conceptualise the construction of architecture and its representation. Beyond the critique of systems through speculative drawing or writing, the mechanics of the game carry architectural messages, even when they are highly abstracted and defined in scope. On one level, this reinforces virtual worlds as places whose 'value is that they allow the co-creation of concepts in an engaging and motivating environment' (Koutsabasis, Vosinakis, Malisova \& Paparounas, 2012). For my own architectural practice there are more levels-the design of this game and all the other pieces of modelling and drawing that goes into constructing the game produces an architectural project that works across multiple levels and media.

\section{Tokyo Backup City: Towards a Videogame Urbanism}

As my design projects have previously discussed, architecture in videogame worlds is modulated in relation to their systems of play. Tokyo Backup City was a design research project produced with [anonymised] that attempted to outline a methodology for design taking the figurative qualities of game spaces and applying them into the design of a conceptual project ostensibly proposed as a 'real world' design.

The project was inspired by an urban plan named Tokyo IRTBBC that was proposed in 2011 by Hajime Ishii of the Japanese Democratic Party, addressing concerns that Tokyo's current density puts it at mortal risk from natural disasters, following the tsunami earlier that year. The IRTBBC (Integrated Resort Tourism Business Backup City) would see the Japanese seat of power moved to an airport site in Osaka in the event Tokyo were destroyed by a natural disaster. While the idea was speculative, 
the NEMIC Committee's scheme was a sterile business park, meaning that while Tokyo's functions might be retained, its urban culture would be lost in such a move. It was also designed to be funded by Integrated Resorts, Las Vegas style gambling complexes that have only recently been legalised in Japan.

We proposed an alternative design for the site, which gamifies the urban realm. The systems it uses are drawn from research into specific Japanese arcade games called medal games, which, like pachinko, are legal gambling machines that do not involve cash transactions (instead using medal tokens). This research has comprised photography, the analysis of patent documents detailing mechanical workings, and a series of drawn studies to build a body of knowledge on machines that are rarely found outside Japan and have had little to no academic study in the West. By applying medal game principles at an urban scale, the project proposes that casino funding sources could instead be generated through a gamified masterplan, as a playful interpretation of smart city technologies [Fig.13]. 


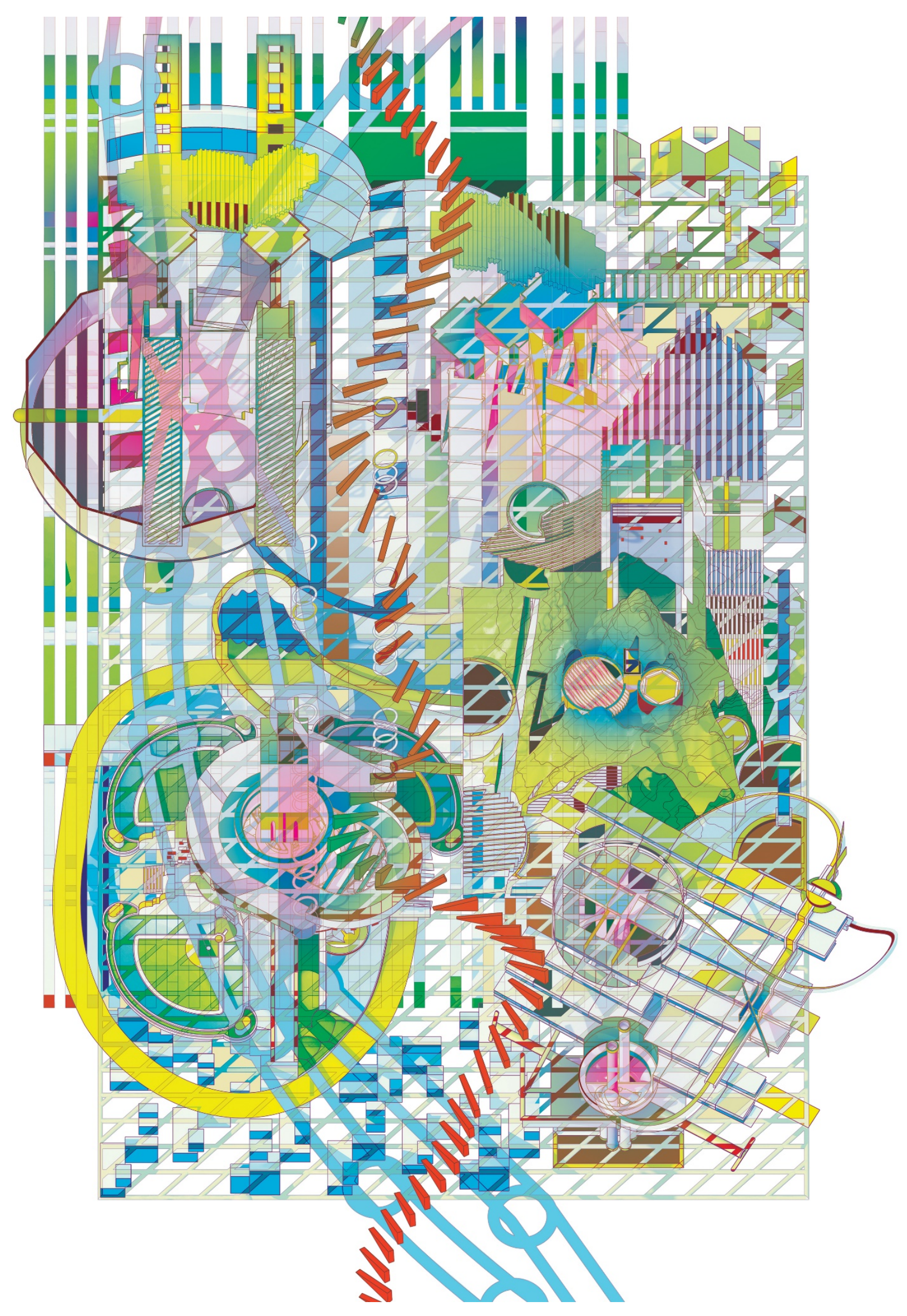


We developed this directly from examples of medal game cabinets we had uncovered, with complex mechanisms for moving balls and tokens, exploring how their game systems might be transposed with specific areas of Tokyo. Our project deliberately abstracted and compressed Tokyo to condense its urban condition, applying approaches elucidated in other projects such as Learning from Los Santos.

The hub structures which we design relate to districts of Tokyo and encode complex legal and cultural systems into gamified caricatures, architectures that amplify certain situations and disavow others. The structures accommodate playful relationships between the information we can now gain from our cities and how we might choose to use it. Given that games such as Pokémon GO have demonstrated the potential of fictional logic systems applied onto real spaces, the project questions the future role games and their fantasies might play in shaping our urban environments. [Fig.14]. 


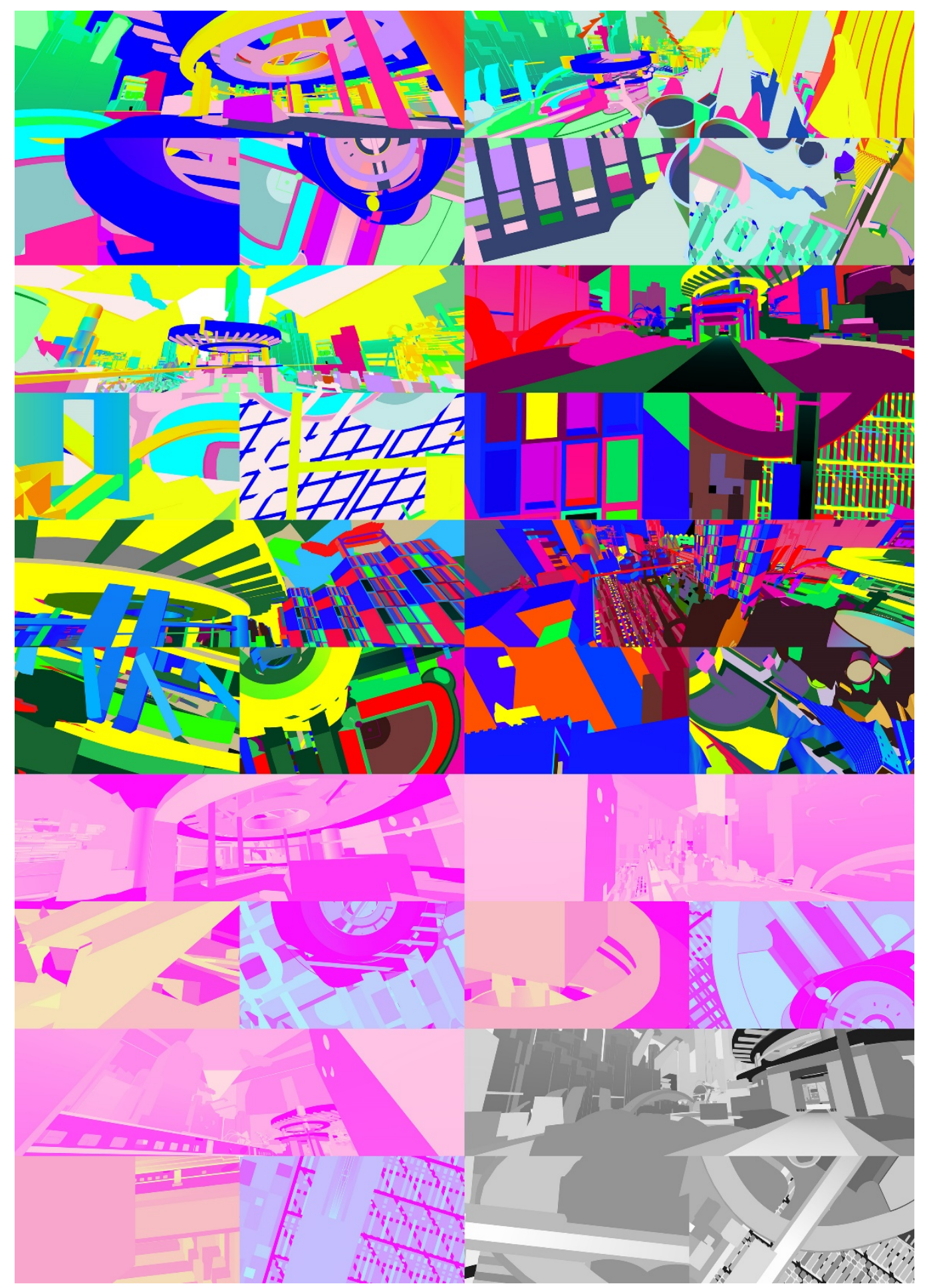

The nature of 'backing up' today, and the design methods behind this as a process, suggest that this city might be sited at least partially in a virtual rather than physical realm. Initiatives such as Rekrei/Project Mosul demonstrate the importance of preserving culture by any means possible, in this case crowd sourced photogrammetry of monuments and objects of historical significance under threat from war and natural disasters. The vast proliferation of virtual objects being sold 
within game worlds also suggests our conception of 'artefact' will be challenged by such technologies. And of course, at a larger scale, the LiDAR scanner is finding increasing ubiquity as a recording device that can produce hyper accurate 3D geometry.

But is the exact geometrical reading of a physical space always the most accurate reading of culture? Los Santos captures the spirit of a city without geographic exactitude. It is through the feeling of playing the game that these qualities are expressed to us. Because games are so adept at exposing us to logic structures and making them comprehensible, we can also imagine their architectural utility in understanding planning processes and the other forces which shape the city. Perhaps game design might start to affect BIM software (that can already be connected to game engines), introducing cultural, social and experiential structures into architectural modelling environments. It is also possible that citizens could be increasingly engaged with the design of cities through gaming apps that allow them to directly participate in the creation and application of laws. Can game systems and fiction be used to make all the new data and information on our environments and objects into something digestible, softer and less technocratic, something that citizens would want to actively engage with?

The project is an investigation into designing a city encoded through the logic of videogames. Although it has a physical site, it is rather unlikely we will ever get to construct it. Instead we use speculative research to question how game technologies can inflect upon architectural design, assuming an agency as a method for designing in the physical. Rather than a constrained backup city preserving Tokyo in the logics of the faceless office block or podium level mall, our design sears itself onto the retina of the landscape, much like the effect Tokyo itself has on anyone who has visited the city and experienced its unique architectural mania. It is a backup for a city where buildings look like microchips, faces and battleships; that could be shaken to death at any moment, collapsing in a rain of neon signs. 


\section{Machines for Playing In}

Throughout this paper I have attempted to delineate an emerging conversation between architecture and videogame design that I am developing through my design research. Many of the formative experiences of architecture that young people have today is through videogame worlds, and we can expect this to affect the aesthetic sensibilities of new generations of architects to come. As I have discussed throughout this paper, a trajectory towards co-opting videogames as a form of architectural representation, and then applying their logics into the design of 'realworld' projects, relies on an understanding of how they transact space. As the meeting point of computational and visual arts cultures they suggest an exciting future. By incorporating narrative and fiction as well as symbolic structures into their worlds, games offer the potential to reinvigorate the type of speculative design projects that proved highly influential to previous generations of architects and challenged the boundaries of the discipline. My personal aim is to incorporate the sensibilities of game worlds into architecture as a way of disrupting some of the dominant digital discourses in architecture by embracing the computer's ability to create the absurd, the intense and the inconsistent.

If computation promises to take architecture to new places in terms of generative systems, digital fabrication or data driven analytics of cities, then my research argues that videogame spaces offer new directions, embracing interactive fictional worlds that can affect reality and that crucially require people. Games can have an agency that can be applied towards social change and engaging people in the design processes of cities. Synthesising game spaces will offer architects new possibilities for speculating on the meaning and experience of architecture, both in the design of their virtual spaces and the ways in which users can inhabit them. These will be architectures where meaning can change frame by frame, where worlds can collide and collapse and extend into infinity. Our concept of space will become precise, yet fluid, synthetically encoded yet naturalistic, fusing the virtual and actual in unprecedented ways. 


\section{Reference List}

Aarseth, E. (2000). Allegories of Space. The Question of Spatiality in Computer Games. In Cybertext Yearbook 2000.

Banham, R. (2009). Los Angeles: The Architecture of Four Ecologies. Berkeley, Los Angeles and London: University of California Press.

Bogost, I \& Klainbaum, D. (2006). In N. Garrelts (Ed.,) The Meaning and Culture of Grand Theft Auto: Critical Essays. Jefferson NC and London: McFarland \& Company. Kindle Edition for iPad.

Bolter, J.D. \& Grusin, R. (2000). Remediation, Understanding New Media. Cambridge MA, London: MIT Press.

Böttger, M., von Borries, F. \& Walz, S. (2007). Space Time Play: Computer Games, Architecture and Urbanism - the Next Level. Basel: Birkhauser.

Carmack, J. (2012). Quoted by Twitter user @me_irl referencing an email conversation with @ID_AA_Carmack (John Carmack) posted 11:50 PM - 16 Nov 2012. "john carmack on "no clipping"”. Accessed $8^{\text {th }}$ February 2019, http://pastebin.com/8sj4RAxq.

Coyne, R. (2003). Mindless repetition: learning from computer games. In Design Studies, Volume 24, Issue 3. London: Elsevier.

Evans, R. (1997). Translations From Drawing to Building and Other Essays. Cambridge MA: The MIT Press.

Flusser, V. (2006). Towards a Philosophy of Photography. London: Reaktion Books.

Grodal, T. (2003). Stories for Eye, Ears, and Muscles: Video games, media, and embodied experiences. In The Video Game Theory Reader. New York: Routledge.

Habraken, N.J. \& Gross, M.D. (1988). Concept design games. In Design Studies, Volume 9, Issue 3.

Huizinga, J. (2003). Homo Ludens: A Study of the Play-Element in Culture. London: Routledge, 2003.

Izenour, S., Scott Brown, D., \& Venturi, R. (1973) Learning From Las Vegas. Cambridge MA, London: MIT Press.

Jencks, C. (2016). Notopia: the Singapore paradox and the style of generic individualism. In Architectural Review, accessed 8th February 2019.

https://www.architectural-review.com/rethink/campaigns/notopia/notopia-thesingapore-paradox-and-the-style-of-generic-individualism/10006923.article.

Jones, D. (2013) 'An Alternative (to) Reality', in Childs, M. and Peachey, A. (eds), Understanding Learning in Virtual Worlds, Human-Computer Interaction Series, London, Springer London, pp. 1-20 [Online]. DOI: 10.1007/978-1-4471-5370-2. 
Juul, J. (2005). Half-Real: Video Games between Real Rules and Fictional Worlds. Cambridge MA, London: MIT Press. Kindle edition for iPad.

Kirkpatrick, G. (2011). Aesthetic Theory and the Videogame. Manchester: Manchester University Press.

Koutsabasis, P., Vosinakis, S., Malisova K., \& Paparounas, N. (2012). On the value of Virtual Worlds for collaborative design. In Design Studies, Volume 33, Issue 4.

Lobo, D.G. (2007). Playing With Urban Life: How SimCity Influences Planning Culture. In Space Time Play: Computer Games, Architecture and Urbanism: The Next Level. Basel: Birkhäuser Verlag.

Macarthur, J. (2007). The Picturesque: Architecture, Disgust and Other Irregularities. London, New York: Routledge.

Manaugh, G. (2016). Zone for Game. In BLDGBLOG. Accessed 14 ${ }^{\text {th }}$ February 2019 http://www.bldgblog.com/2016/08/zone-for-game/

Manovich, L. (2013). Software Takes Command. New York, London: Bloomsbury.

Manovich, L. (2001). The Language of New Media. Cambridge MA, London: MIT Press

May, S. (2019). The Power of Cute. Princeton NJ: Princeton University Press.

Molleindustria.org. (2017). Nova Alea. Accessed 14th February 2019, http://molleindustria.org/nova-alea/

Niantic Labs. Gather Poké Balls, Potions \& Eggs. Accessed 20th January 2019, https://support.pokemongo.nianticlabs.com/hc/en-us/articles/221957688-GatherPok\%C3\%A9-Balls-Potions-Eggs.

Nitsche, M. (2008). Video Game Spaces. Cambridge MA, London: MIT Press.

Owens, C. The Allegorical Impulse: Towards a Theory of Postmodernism. In October, Vol.12 (Spring, 1980). Cambridge, MA: MIT Press.

Radford, A. (2000). Games and learning about form in architecture. In Automation in Construction, Volume 9, Issue 4. London: Elsevier.

Reynolds, D. (2010). Virtual World Naturalism. In The Fiberculture Journal Issue 16: Counterplay. Accessed 20th December 2018, http://sixteen.fibreculturejournal.org/virtual-world-naturalism/.

Salen, K., \& Zimmerman, E. (2003). Rules of Play. Cambridge MA, London: MIT Press.

Sharp, J. (2015). Works of Game. Cambridge MA, London: MIT Press.

Stuart, K. "No Man's Sky is Elite for the 21st century. Pointless? Maybe - but also sublime", The Guardian, accessed 20th February 2019, https://www.theguardian.com/technology/2016/aug/19/no-mans-sky-elite.

Walz, S. (2010). Towards a Ludic Architecture. Pittsburgh PA : ETC Press. 
Williams, F. (2015). The Guardian Cities: Skylines challenge - can I build a truly anticapitalist city? In The Guardian. Accessed 10 ${ }^{\text {th }}$ February 2019.

https://www.theguardian.com/cities/2015/aug/06/guardian-cities-skylines-challengebuild-anti-capitalist-post-growth-city

Worldcraft: Bjarke Ingels (Future of StoryTelling 2014) (9th Sept, 2014), YouTube video, added by Future of Storytelling. Available at https://www.youtube.com/watch?v=pyNGDWnmX0U [5 $5^{\text {th }}$ May 2019].

Venturi, R. (1977). Complexity and Contradiction in Architecture. New York: The Museum of Modern Art Papers on Architecture.

\section{List of Figures}

Fig.01: Diagram analysing Pokémon GO interface. Diagram and screenshot by author (taken in Kyoto, Japan).

Fig.02: Screenshot from Half-Life 2 (2004, Valve Corporation). Taken by author.

Fig.03: Drawing by author, pen and ink, derived from screenshot photography.

Fig.04: Drawing by author, pen and ink, derived from screenshot photography.

Fig.05: Drawing by author, pen and ink, derived from screenshot photography.

Fig.06: Drawings by author, pen and ink, derived from screenshot photography.

Fig.07: Map produced by author, digital drawing.

Fig.08: Google Earth overlay produced by author, digital drawing.

Fig.09: Three-dimensional map produced by author, digital drawing.

Fig.10: Digital image of game and architectural fragments by author.

Fig.11: Diagram by author showing gesture recognition process.

Fig.12: Diagram by author showing in-game image creation.

Fig.13: Drawing of the Tokyo Backup City masterplan by [anonymised].

Fig.14: Screenshots from a game-based version of the Tokyo Backup City masterplan by [anonymised]. 